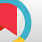

\title{
Overlapping of Asthma and Chronic Obstructive Pulmonary Disease:
} A Literature Review

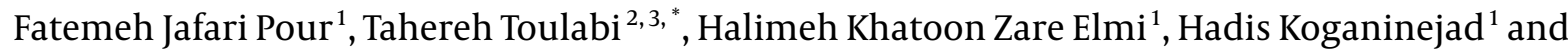 \\ Leila Jafaripour ${ }^{4,5}$ \\ ${ }^{1}$ Student Research Committee, School of Nursing and Midwifery, Lorestan University of Medical Sciences, Khorramabad, Iran \\ ${ }^{2}$ Social Determinants of Health Research Center, Lorestan University of Medical Sciences, Khorramabad, Iran \\ ${ }^{3}$ Department of Nursing, School of Nursing and Midwifery, Lorestan University of Medical Sciences, Khorramabad, Iran \\ ${ }^{4}$ Department of Anatomy, School of Medicine, Dezful University of Medical Sciences, Dezful, Iran \\ ${ }^{5}$ Department of Anatomical Science, Afzalipour Medical School, Kerman University of Medical Sciences, Kerman, Iran \\ "Corresponding author: Social Determinants of Health Research Center, Lorestan University of Medical Sciences, Khorramabad, Iran. Postal Code: 6813833946, Tel: \\ +98-6633120140, Fax: +98-6633120140, E-mail: tolabi.t@lums.ac.ir
}

Received 2018 August 17; Revised 2018 November 27; Accepted 2018 December 20.

\begin{abstract}
Asthma and chronic obstructive pulmonary disease (COPD) are the most common chronic respiratory diseases with significant morbidity in the world. Although these diseases have different characteristics, some patients share symptoms and clinical findings of both diseases, so-called asthma-COPD overlap syndrome (ACOS). Although there is no gold standard for the diagnosis of ACOS, it is usually defined as an increased variability of airflow in the respiratory tract. Patients with ACOS are identified with distinct phenotypes such as the increased reversibility of airflow obstruction, eosinophilic bronchial and systemic inflammation, and the increased reaction to inhaled corticosteroids compared to COPD patients. The evidence indicates that ACOS patients are likely to have more dyspnea and cough, more serious symptoms, more hospital admissions, and higher mortality rate. Despite these complex conditions, ACOS patients have been eliminated from clinical trials of asthma and COPD and there is little evidence about their clinical decisions. The current study was conducted to review the epidemiology, clinical symptoms, diagnosis, and treatment of ACOS as the first stage of correct diagnosis and appropriate management of this syndrome in databases such as PubMed, Elsevier, Google Scholar, SID, Magiran, Google search engine, and so on.
\end{abstract}

Keywords: ACOS, Asthma, COPD, Diagnosis, Treatment

\section{Context}

Asthma and chronic obstructive pulmonary disease (COPD) are identified by airflow limitation and chronic airway inflammation (1-3). Asthma usually has a sudden onset, alternate symptoms, and an appropriate response to inhaled treatments and with other allergic disorders. In contrast, COPD has a gradual onset and gives a weak response to inhaled treatments, and is associated with chronic smoking (4). Most physicians are able to discriminate asthma from COPD, but it is difficult to reach an ultimate diagnosis in some patients due to sharing the characteristics of both diseases (5-7), which is so-called asthmaCOPD overlap syndrome (ACOS) (4). ACOS was introduced as a syndrome with asthma and COPD characteristics in both Global Initiative for Asthma (GINA) and Global Initiative for Chronic Obstructive Lung Disease (GOLD) guidelines, as well as in clinical practice guidelines in 2014 (8). ACOS is a tempting syndrome with distinct phenotypes such as (1) the first diagnosis of COPD with eosinophilic inflammation, (2) the first diagnosis of asthma with neutrophilic inflammation, serious inhalation disorder, and the history of smoking cigarettes and, (3) the first diagnosis of asthma with irreversible obstruction of the airflow due to structural changes (4). Indeed, it is difficult to identify the syndrome with such distinct phenotypes and it requires a comprehensive method such as the assessment of clinical characteristics, spirometry with bronchodilator test, diagnosis of eosinophilic inflammation, assessment of lung volumes, carbon monoxide diffusion capacity, and CT scan (9).

The prevalence of ACOS has been reported differently in various studies depending on the given definitions of the disease. However, in current studies, it is estimated to be $15 \%$ to $25 \%$ (10-14). The epidemiologic studies indicated that ACOS is observed more among women. The mean age of ACOS patients was 64 years that was greater than the 
mean age of asthma patients and lower than that of COPD patients $(15,16)$. An Italian study using the spirometry assessment of 1065 patients revealed that almost $11.1 \%$ of the patients had ACOS, 14.9\% had asthma, and 19.3\% had COPD (17). In the United States, the same prevalence of ACOS was reported in the $15.8 \%$ of patients admitted to general pulmonary clinics (14). The prevalence of ACOS has recently been reported as 3.2\% in the United States (15). As ACOS patients have acute respiratory symptoms and lower life quality compared to asthma and COPD patients (12-18) and they have a greater rate of hospital admission and use of healthcare services (15), it seems necessary to review the definitions, pathophysiology, epidemiology, clinical symptoms, treatment, and diagnosis of this syndrome as the first step toward the identification and careful, optimal recognition of the disease and its correct management.

\section{Evidence Acquisition}

This literature review was conducted using keywords such as ACOS, asthma, and COPD in Persian databases, i.e. SID and Magiran, and keywords such as COPD, asthma, ACOS, clinical characteristics, diagnosis, epidemiology, pathology, and treatment in the international databases such as PubMed, Elsevier, and Google Scholar, as well as Google search engine, without any time limitation. The inclusion criteria included published in English or Persian language, availability of the full-text, having the given titles or keywords, and relevancy. The exclusion criteria include not being published in English or Persian, not having access to the full text of the article, and being irrelevant to the field of study. With regard to the purpose of the study, searching in the Persian databases led to no result and the results were limited to English databases. As a result, 75 relevant articles were collected by meticulous analysis of articles obtained from the initial extraction.

\section{Results}

\subsection{The Definition of ACOS}

There is no worldwide definition for ACOS, but several studies have attempted to provide a definition for it. Gibson and Simpson considered ACOS as the increased variability of airflow and incomplete reverse of airflow obstruction (5). Brzostek and Kokot defined ACOS as a phenotype of characteristics of both asthma and COPD (19). Louie et al. introduced asthma associated with partial reversibility of airflow obstruction with emphysema and reduction of carbon monoxide diffusion capacity to less than $80 \%$ (13). Chung et al. defined this syndrome as FEV1/FVC $<0.70$ and a historical report of wheeze (20). In contrast,
Izquierdo-Alonso et al. introduced it as COPD and provided a 40-year history of asthma (21). de Marco et al. defined ACOS as the diagnosis of both asthma and COPD (COPD diagnosis, emphysema, or chronic bronchitis) (22). In a retrospective cohort study, Lee et al. considered ACOS as the initial diagnosis of asthma (bronchodilator reversibility test with a $12 \%$ or $200 \mathrm{~mL}$ increase in FEV1 and positive methacholine/mannitol challenge test) with $0.70>$ FEV1/FVC after prescription of bronchodilator in the initial assessment and continuous obstruction of airflow after three months of follow-up (23). In another study, Kauppi et al. defined this syndrome as sharing the characteristics of both asthma and COPD based on the GINA and GOLD guidelines (12). Menezes et al. considered patients as ACOS when they had the asthma disease criteria including wheezing at least for 12 months and a $12 \%$ or $200 \mathrm{~mL}$ increase in FEV after prescription of bronchodilator and the doctor's diagnosis of both asthma and COPD with $0.70>$ FEV1/FVC after prescription of bronchodilator (24). Pleasants et al. defined ACOS as sharing the diagnosis of both asthma and COPD (25). Milanese et al. diagnosed patients with ACOS among those who were above 65 years of age and associated with the initial diagnosis of asthma based on the GINA guideline and chronic respiratory disease with the total diffusion capacity of lower than $80 \%$ (7). In contrast, Miravitlles defined ACOS patients based on $0.70>$ FEV/FVC after prescription of bronchodilator with a diagnosis of asthma before 40 years of age (26). Zeki et al. defined it as two clinical phenotypes: (1) asthma with partial reversibility of airflow obstruction with or without emphysema and reduction of carbon monoxide diffusion capacity to $80 \%$ and (2) COPD with emphysema and partial reversibility of airflow obstruction with or without environmental allergy (14).

The ACOS definition has also been given in some guidelines. According to the Spanish COPD guideline, four phenotypes including non-exacerbator with emphysema or chronic bronchitis, asthma overlapping with COPD, emphysema, and exacerbator chronic bronchitis have been introduced (27). This guideline defines ACOS patients based on major and minor criteria. The major criteria include a very positive bronchodilator response (a $15 \%$ or 400 $\mathrm{mL}$ increase in FEV1), sputum eosinophilia, or a previous history of asthma. The minor criteria include the increase of total serum IgE and a previous history of atopy or positive bronchodilator response (a $12 \%$ or $200 \mathrm{~mL}$ increase in FEV1). To recognize ACOS, a patient must have two major criteria or one major plus two minor criteria $(28,29)$. The Czech Republic and Finnish guidelines have also introduced criteria for ACOS. The major diagnostic criteria in the Czech Republic guideline include a very positive bronchodilator response (a $15 \%$ or $400 \mathrm{~mL}$ increase in FEV1), a positive bronbronchial test, sputum eosinophilia $>3 \%$ 
(FeNO > $45-50 \mathrm{ppb}$ ), and a previous history of asthma while the minor criteria include positive bronchodilator (a 12\% or $200 \mathrm{~mL}$ increase in FEV1), the increase of total serum IgE, and a history of atopy (30). The major diagnostic criteria in the Finnish guideline include very positive bronchodilator (a $15 \%$ or $400 \mathrm{~mL}$ increase in FEV1), sputum eosinophilia or the increase of $\operatorname{ENO}(>50 \mathrm{ppb})$, or previous asthma symptoms (before the age of 40) while the minor criteria included the increase of total serum IgE, atopy, a positive bronchodilator response(a $12 \%$ or $200 \mathrm{~mL}$ increase in FEV1), or a previous history of asthma (31). According to the two guidelines, each patient must have two major criteria or one major plus two minor criteria to be recognized as an ACOS patient. Recent documents of GINA and GOLD guidelines on ACOS have defined it as a continuous obstruction of airflow with prominent characteristics of asthma and COPD $(8,32)$.

\subsection{Pathogenesis and Pathophysiology}

Although ACOS pathogenesis is unknown, it is believed that ACOS more accompanies respiratory tract diseases than COPD alone. In other words, it shares the symptoms of both asthma and COPD. Pathophysiologically, COPD is usually identified with inflammation, wall thickness changes of the small airway, and destruction of respiratory and terminal bronchioles, leading to emphysematous changes of the lungs (33). The inflammation process of COPD includes the increase of the number of CD8 associated with TC1 lymphocytes in smokers. Moreover, the inflammatory airways of COPD patients include macrophages, T lymphocytes, and dendritic cells (34). Furthermore, the lack of Alpha 1 antitrypsin, the only known genetic factor of COPD, can cause emphysema pan lobular and airway changes (35). Asthma is usually identified with inflammation and changes of both major and minor airways. Parenchymal changes are rare in asthma and can be observed in very serious life-threatening cases (36). The inflammation in asthma induced by eosinophilic and the production of pro-inflammatory transmitters and basic proteins lead to the injury of epithelial cells and airway remodeling. In addition, other cells such as lymphocytes, mast cells, dendritic cells, and macrophages play roles in the inflammation process and help it to occur (34). Overall, the inflammation process of airways in asthma differs from that of COPD; in asthma, it is related to eosinophils activity and Th2 cells while neutrophils play an important role in COPD. However, recent evidence indicates that most asthma patients, especially older patients with moderate to severe symptoms, have significant neutrophils in their airways whereas more than 30 to $40 \%$ of COPD patients show many eosinophils in both sputum and blood (37).
Christenson et al. through the assessment of small airway piles of COPD patients found out that the genomic nature of asthma including involved genes in the inflammatory route of Th2 in the airways of COPD patients was enriched compared to health and smoker groups. Generally, COPD patients who had higher expressions of Th2 gene on bronchial piles indicated greater bronchodilator reversibility, greater environmental and tissue eosinophils, and more desirable responses to inhaled corticosteroids compared to other patients who did not have this biological indicator (38). These biological indicators in COPD patients' airways can be used as criteria for the diagnosis of ACOS.

ACOS patients may show greater airway disorders compared to emphysemic and smoking counterparts. Genetic specialists with careful assessment of phenotypes of ACOS and COPD patients discovered that ACOS patients share more acute inhalator symptoms associated with more recurrence periods, lower emphysema, and thicker septum of the airways. Finally, some researchers such as Hardin et al. with the application of genetic analysis of ACOS patients came to significant findings of the relationship between CSMD, SOX, and GPR (39).

\subsection{Epidemiology}

In different studies, the reported prevalence of ACOS was dependent on the given definitions for COPD and asthma, the population sampled, and age groups (8). In a cross-sectional study with 279 COPD patients, Miravitlles et al. reported the prevalence of ACOS as 5\% (40). In a wider measurement survey with 3125 COPD patients with the same criteria, the prevalence of ACOS was reported as 3.9\%, and regarding the previous diagnostic criteria of asthma, it rose to $15.9 \%$ (41). In a retrospective study on 499 COPD patients, the same prevalence (5\%) was indicated among smoking patients (42). In addition, in Izquierdo-Alonso et al. study, a $12 \%$ prevalence of ACOS was reported among 331 patients who referred to outpatients pulmonary clinics (21). In a study, Hardin et al. found out that $13 \%$ of COPD patients shared asthma symptoms (43). In the epidemiologic studies such as PLATINO in Latin America, the prevalence of $81.6 \%$ with the criterion of $0.70>$ FEV1/FVC after prescription of bronchodilator and asthma diagnosis was reported (24). In another epidemiologic study in Spain, regarding COPD patients and previous asthma diagnosis (before the age of 40 ), the prevalence of $17.4 \%$ was observed among COPD patients (26). Generally, its prevalence has been reported about 15 to $20 \%$ in the cohort studies of research databases of UK, US, and other Italian and Finnish studies using more than 40-year samples $(10,25,44)$. 


\subsection{Clinical Symptoms}

Generally, ACOS patients have severe respiratory symptoms, greater physical problems, and a higher rate of hospital admission compared to asthma and COPD patients $(22,26,41,45)$. In a cross-sectional study on 8360 patients (20 to 84-years-old) in four pulmonary clinical centers of Italy, de Marco et al. divided patients into four groups of asthma, COPD, ACOS, and NOD based on questionnaire data. Their research findings revealed that the prevalence of dyspnea was greater in ACOS patients (39\%) than in COPD (21\%) and asthma (9\%) groups. Furthermore, they found that the prevalence of symptoms such as a cough, sputum, and wheezing was greater in ACOS patients than in COPD and asthma patients whereas the asthma group showed a greater prevalence of rhinitis compared to the ACOS group (22). Brzostek and Kokot conducted a study on 12103 smoking patients (above 40 years of age) to recognize the specific symptoms of ACOS patients and found that about $68 \%$ of the patients had exertional dyspnea associated with COPD symptoms while another $68 \%$ had exertional dyspnea with asthma characteristics such as wheezing. Moreover, $72 \%$ of the patients had a chronic productive cough like COPD patients (19). Milanese et al. conducted a descriptive study on pulmonary and allergenic problems among 350 old patients (age > 65) in 16 clinics for six months in 2012 - 2013. 101 patients were identified with ACOS based on questionnaire data and clinical examinations. They observed that about $84 \%$ of the ACOS patients had chronic bronchitis and the prevalence of dyspnea was significantly greater among them compared to the asthma group $(\mathrm{P}>$ $0.001)(7)$.

Miravitlles et al. conducted an epidemiologic study on 3885 patients who referred to seven pulmonary caring clinics. 385 patients were identified with COPD and 67 patients with ACOS. According to their findings, ACOS patients had more frequent exertional dyspnea compared to COPD patients $(P>0.001)$. In addition, wheezing symptoms were more reported among these patients $(P>0.001)$. However, there was no significant difference between the groups in terms of coughing and sputum production (26). Menezes et al. in a cross-sectional study of 5044 patients in Latin America reported the highest prevalence of coughing and sputum in the ACOS group. 89 patients were identified with ACOS while other participants were classified into COPD, asthma, and NOD groups. According to their report, the asthma group had the highest prevalence of dyspnea ( $P$ $>0.001)$. Wheezing was observed in all asthma and ACOS patients and only in $29 \%$ of COPD patients ( $\mathrm{P}>0.001)$ (24).

In a retrospective study in North Carolina in 2007 2009, Pleasants et al. collected data on asthma and COPD through phone calls and interviews. 24073 people participated in the study and they were divided into five groups:
Previous asthma, recent asthma, COPD, no obstructive lung disease (NOD), and ACOS. 807 patients were identified with ACOS that had more exertional dyspnea and lower quality of life compared to other groups (25).

\subsection{Diagnosis}

There is no comprehensive definition for ACOS and it is known by different names such as overlap syndrome of asthma and COPD, mixed asthma-COPD phenotype, asthma combined with COPD, the coexistence of asthma and COPD, and COPD with asthmatic features (46). In previous studies, the prevalence of ACOS varies considerably because it has been diagnosed based on different criteria (47-50). ACOS is currently a diagnostic challenge for physicians because there are no definite diagnostic criteria to differentiate it from asthma and COPD (11). Since a single factor such as a respiratory symptom or a spirometric parameter is not able to differentiate between asthma, COPD, and ACOS (51), some major and minor criteria have been suggested for diagnosing ACOS $(40,42)$. However, these diagnostic criteria are not definitive and physicians usually change diagnosis during follow-up (46). In addition, the diagnostic criteria of ACOS advocated by GINA/GOLD are somewhat complicated and there are limited data regarding how ACOS patients respond to current medications (52). Thus, this paper reviews the diagnostic criteria and biomarkers of ACOS used in previous studies and propose practical approaches for diagnosing ACOS.

Most studies defined ACOS as a phenotype of COPD. The most important diagnostic characteristic of ACOS in the ACOS patients is the appearance of sputum eosinophilia. The inflammation in asthma patients is mainly eosinophilic and induced by $\mathrm{T}$ lymphocytes and CD4 while the inflammation in COPD is neutrophilic and caused by CD8 (53). In addition, in COPD patients, the increased reversibility is the key in the diagnosis of ACOS patients. The significant reversibility is one of the COPD characteristics usually observed in the patients' clinical examinations (54). More than 50\% of moderate to severe COPD patients respond well to bronchodilator in the acute stages (55).

Since the sputum eosinophilia has not been assessed in clinical practice, other indirect markers of the inflammation, such as nitric oxide and Immunoglobulin E (IgE), have been considered (56). Chou et al. indicated the higher levels of nitric oxide in COPD patients and eosinophilia inflammation of the airway ( $3 \%<$ sputum eosinophilia) with ENO of $23.5 \mathrm{ppb}$, the sensitivity of $61.2 \%$, and specificity of $70.5 \%$ for the diagnosis of eosinophilia inflammation (57).

Other plasma and sputum biomarkers have recently been considered. According to Iwamoto et al., four 
biomarkers of COPD including surfactant protein A (SPA), soluble receptor for advanced glycation end products (sRAGE), myeloperoxidase, and neutrophil gelatinaseassociated lipocalin (NGAL) can help in its diagnosis. The MPO of sputum and SP-A of plasma in asthma patients show significant rises compared to ACOS patients whereas only increases NGAL compared to COPD patients (58). Huang et al. found that inflammatory cytokines such as IL4, IL-8, IL-10, and TNF-a are different in asthma, COPD, and ACOS patients and can be useful in the assessment of these diseases (59).

The genetic analysis of COPD gene has identified several differences associated with ACOS that indicate genetic risk factors (39). Christenson et al. considered the increase of gene signatures associated with asthma in COPD patients and characteristics associated with asthma as eosinophilic inflammation and Th2. They created 100 gene signatures from Th2-related gene expression. For example, they discovered that T2S had a good relationship with Th2 and the increase of T2S-related gene expression was indicated in more than $20 \%$ of COPD patients. Generally, T2S is associated with the increase of bronchodilator response and the decrease of inflammation after treatment with a bronchodilator (38).

The diagnosis of ACOS should be considered according to the following criteria (60):

(1) Clinical manifestations of both asthma and COPD.

(2) Persistent airway obstruction, post-bronchodilator, and FEV1/FVC $<0.7$ evaluated in the period of clinical stability.

(3) A positive response to the bronchodilator test and an increase in the volume of FEV $1 \geq 200 \mathrm{~mL}$ or $\geq 12 \%$ from baseline.

(4) A history of smoking or exposure to biomass combustion.

Clearly defined criteria for the diagnosis of ACOS are important. ACOS patients probably demonstrate specific clinical and functional trajectories with more severe disease and worse prognosis compared to asthma and COPD patients. For example, ACOS patients have a higher frequency of exacerbations and subsequent hospitalizations, which result in significantly higher healthcare costs compared to patients with asthma or COPD (61). There are also indications that ACOS patients display a systemic disease with inflammation $(50,62)$ and may have an increased risk for the development of non-respiratory cancers (63). In addition, the societal burden affecting daily activities is believed to be more important in ACOS compared to asthma or COPD (64). Finally, physicians are able to build a complete picture of the disease and start to think of individual disease phenotypes and appropriate treatment (46).

\subsection{Treatment}

There is no obvious treatment for ACOS. In other words, there is little data about ACOS patients' responses to most pharmacological treatments because they have been eliminated from clinical trials of both asthma and COPD recently (65). Overall, the treatment must include smoking cessation, pulmonary rehabilitation, oxygen supplementation, vaccination, and disease management (34). According to Japanese COPD guidelines, the first-line treatment for ACOS includes the combination of long-acting beta2agonists (LABA) and inhaled corticosteroids (ICS) without consideration of the obstructive levels of the airway (66). However, Spanish, Czech Republic, and Finnish COPD guidelines only focus on the prescription of ICS for ACOS patients $(30,31)$.

Several studies have been performed to identify the most effective pharmacological treatments for this syndrome. One clinical trial assessed Tiotropium impacts on 472 ACOS patients. In this study, the improvement of lung function and the decreased use of rescue medications in treatment with Tiotropium were revealed (24). Some studies have indicated that COPD patients with eosinophilic inflammation, being treated with ICS, had a significant improvement in bronchial inflammation and spirometry results $(67,68)$. Two clinical trials indicated that the prescription of corticosteroids (oral or inhaled) based on the intensity of eosinophilia inflammation in COPD patients could significantly be effective in the prevention of intensive symptoms and improvement of life quality $(69,70)$.

Moreover, new treatments are developing to decrease the density of eosinophilia. However, anti-IL5 benralizumab led to the decrease of intensive symptoms and improvement of FEV1 findings in patients with a high level of eosinophilia while it did not decrease the intensive symptoms in COPD patients with peripheral eosinophilia; however, further research is strongly recommended (71).

We can refer to theophylline (72), phospodiasteraze 4 inhibitors (PDEI) (73), leukotriene modifiers (74), shortacting and long-acting muscarinic agents (34), and mast cell stabilizers (75) as other recommended drugs for the improvement of ACOS.

\section{Conclusions}

ACOS patients have three clinical characteristics including increased pulmonary and systemic eosinophilic inflammation, increased reversibility of the airflow, and increased response to ICS compared to COPD patients that help us to identify them. Although ACOS shares both asthma and COPD symptoms, some clinical characteristics and prognosis are different among them and they respond 
better to ICS. Generally, these patients show a higher rate of intensive risk symptoms, a higher rate of hospital admissions, a lower rate of the rapid pulmonary function, and higher rate of mortality compared to asthma and COPD patients. Despite the complex conditions and weak prognosis of these patients, there is little evidence on their pharmacological decisions in the literature. However, according to a general agreement, inhaled corticosteroids may be effective in these patients, but there is little evidence on this case. With regard to very difficult conditions of ACOS patients, it seems necessary to conduct further clinical trials to recognize the best medical method for these patients. In addition, it is necessary to use simple and lowcost markers to recognize ACOS patients quickly and finally choose the best medical method.

\section{Acknowledgments}

We would like to thank everyone who helped us with this research.

\section{Footnotes}

Authors' Contribution: The study conception and design: Fatemeh Jafari Pour, Tahereh Toulabi, Halimeh Khaton Zare Elmi, Hadis Koganinejad, and Leila Jafaripour; manuscript writing: Fatemeh Jafari Pour, Tahereh Toulabi, Halimeh Khaton Zare Elmi, Hadis Koganinejad, and Leila Jafaripour.

Conflict of Interests: The authors declare that they have no conflict of interests.

Financial Disclosure: No financial interests related to the material in the manuscript are declared.

Funding/Support: None declared.

\section{References}

1. Geneva Infant Feeding Association. The global strategy for asthma management and prevention. Geneva: Geneva Infant Feeding Association; 2014.

2. Global Initiative for Chronic Obstructive Lung Disease. Global strategy for the diagnosis, management and prevention of COPD. Global Initiative for Chronic Obstructive Lung Disease; 2014.

3. Nakawah MO, Hawkins C, Barbandi F. Asthma, chronic obstructive pulmonary disease (COPD), and the overlap syndrome.JAm Board Fam Med. 2013;26(4):470-7. doi: 10.3122/jabfm.2013.04.120256. [PubMed: 23833163].

4. Barnes PJ. Asthma-COPD Overlap. Chest. 2016;149(1):7-8. doi: 10.1016/j.chest.2015.08.017. [PubMed: 26757281].

5. Gibson PG, Simpson JL. The overlap syndrome of asthma and COPD: What are its features and how important is it? Thorax. 2009;64(8):72835. doi: 10.1136/thx.2008.108027. [PubMed: 19638566].
6. Global Initiative for Chronic Obstructive Lung Disease. Diagnosis of diseases of chronic airflow limitation: Asthma COPD and asthma-COPD overlap syndrome (ACOS) based on the global strategy for asthma management and prevention and the global strategy for the diagnosis, management and prevention og COPD. Global Initiative for Chronic Obstruc tive Lung Disease; 2014. 15 p.

7. Milanese M, Di Marco F, Corsico AG, Rolla G, Sposato B, Chieco-Bianchi $\mathrm{F}$, et al. Asthma control in elderly asthmatics. An Italian observational study. Respir Med. 2014;108(8):1091-9. doi: 10.1016/j.rmed.2014.05.016. [PubMed: 24958604].

8. Bateman ED, Reddel HK, van Zyl-Smit RN, Agusti A. The asthmaCOPD overlap syndrome: Towards a revised taxonomy of chronic airways diseases? Lancet Respir Med. 2015;3(9):719-28. doi: 10.1016/S22132600(15)00254-4. [PubMed: 26255108].

9. Miravitlles M, Alcazar B, Alvarez FJ, Bazus T, Calle M, Casanova C, et al. What pulmonologists think about the asthma-COPD overlap syndrome. Int J Chron Obstruct Pulmon Dis. 2015;10:1321-30. doi: 10.2147/COPD.S88667. [PubMed: 26270415]. [PubMed Central: PMC4507793].

10. Andersen H, Lampela P, Nevanlinna A, Saynajakangas O, Keistinen T. High hospital burden in overlap syndrome of asthma and COPD. Clin Respir J. 2013;7(4):342-6. doi: 10.1111/crj.12013. [PubMed: 23362945].

11. Barrecheguren $M$, Esquinas $C$, Miravitlles $M$. The asthma-chronic obstructive pulmonary disease overlap syndrome (ACOS): Opportunities and challenges. Curr Opin Pulm Med. 2015;21(1):74-9. doi: 10.1097/MCP.0000000000000118. [PubMed: 25405671].

12. Kauppi P, Kupiainen H, Lindqvist A, Tammilehto L, Kilpelainen M, Kinnula VL, et al. Overlap syndrome of asthma and COPD predicts low quality of life. J Asthma. 2011;48(3):279-85. doi: 10.3109/02770903.2011.555576. [PubMed: 21323613].

13. Louie S, Zeki AA, Schivo M, Chan AL, Yoneda KY, Avdalovic M, et al. The asthma-chronic obstructive pulmonary disease overlap syndrome: Pharmacotherapeutic considerations. Expert Rev Clin Pharmacol. 2013;6(2):197-219. doi:10.1586/ecp.13.2. [PubMed: 23473596].

14. Zeki AA, Schivo M, Chan A, Albertson TE, Louie S. The asthma-COPD overlap syndrome: A common clinical problem in the elderly.J Allergy (Cairo). 2011;2011:861926. doi: 10.1155/2011/861926. [PubMed: 22121384] [PubMed Central: PMC3205664].

15. Kumbhare S, Pleasants R, Ohar JA, Strange C. Characteristics and prevalence of asthma/chronic obstructive pulmonary disease overlap in the United States. Ann Am Thorac Soc. 2016;13(6):803-10. doi: 10.1513/AnnalsATS.201508-554OC. [PubMed: 26974689].

16. van Boven JF, Roman-Rodriguez M, Palmer JF, Toledo-Pons N, Cosio BG, Soriano JB. Comorbidome, pattern, and impact of asthmaCOPD overlap syndrome in real life. Chest. 2016;149(4):1011-20. doi: 10.1016/j.chest.2015.12.002. [PubMed: 26836892].

17. Sorino C, Pedone C, Scichilone N. Fifteen-year mortality of patients with asthma-COPD overlap syndrome. Eur J Intern Med. 2016;34:72-7. doi: 10.1016/j.ejim.2016.06.020. [PubMed: 27357368].

18. Kurashima K, Takaku Y, Ohta C, Takayanagi N, Yanagisawa T, Sugita Y. COPD assessment test and severity of airflow limitation in patients with asthma, COPD, and asthma-COPD overlap syndrome. Int J Chron Obstruct Pulmon Dis. 2016;11:479-87. doi: 10.2147/COPD.S97343. [PubMed: 27019598]. [PubMed Central: PMC4786066].

19. Brzostek D, Kokot M. Asthma-chronic obstructive pulmonary disease overlap syndrome in Poland. Findings of an epidemiological study. Postepy Dermatol Alergol.2014;31(6):372-9. doi:10.5114/pdia.2014.47120. [PubMed: 25610352]. [PubMed Central: PMC4293393].

20. Chung JW, Kong KA, Lee JH, Lee SJ, Ryu YJ, Chang JH. Characteristics and self-rated health of overlap syndrome. Int J Chron Obstruct Pulmon Dis. 2014;9:795-804. doi: 10.2147/COPD.S61093. [PubMed: 25092973]. [PubMed Central: PMC4113567].

21. Izquierdo-Alonso JL, Rodriguez-Gonzalezmoro JM, de Lucas-Ramos P, Unzueta I, Ribera X, Anton E, et al. Prevalence and characteristics of three clinical phenotypes of chronic obstructive pulmonary disease (COPD). Respir Med. 2013;107(5):724-31. doi:10.1016/j.rmed.2013.01.001. [PubMed: 23419828].

Jundishapur J Chronic Dis Care. 2018; 7(4):e83401. 
22. de Marco R, Pesce G, Marcon A, Accordini S, Antonicelli L, Bugiani M, et al. The coexistence of asthma and chronic obstructive pulmonary disease (COPD): Prevalence and risk factors in young, middle-aged and elderly people from the general population. PLoS One. 2013;8(5). e62985. doi: 10.1371/journal.pone.0062985. [PubMed: 23675448]. [PubMed Central: PMC3651288].

23. Lee HY, Kang JY, Yoon HK, Lee SY, Kwon SS, Kim YK, et al. Clinical characteristics of asthma combined with COPD feature. Yonsei Med J. 2014;55(4):980-6. doi: 10.3349/ymj.2014.55.4.980. [PubMed: 24954327]. [PubMed Central: PMC4075403].

24. Menezes AMB, Montes de Oca M, Perez-Padilla R, Nadeau G, Wehrmeister FC, Lopez-Varela MV, et al. Increased risk of exacerbation and hospitalization in subjects with an overlap phenotype: COPD-asthma. Chest. 2014;145(2):297-304. doi: 10.1378/chest.13-0622. [PubMed: 24114498].

25. Pleasants RA, Ohar JA, Croft JB, Liu Y, Kraft M, Mannino DM, et al. Chronic obstructive pulmonary disease and asthma-patient characteristics and health impairment. COPD. 2014;11(3):256-66. doi: 10.3109/15412555.2013.840571. [PubMed: 24152212].

26. Miravitlles M, Soriano JB, Ancochea J, Munoz L, Duran-Tauleria E, Sanchez G, et al. Characterisation of the overlap COPD-asthma phenotype. Focus on physical activity and health status. Respir Med. 2013;107(7):1053-60. doi: 10.1016/j.rmed.2013.03.007. [PubMed: 23597591].

27. Papaiwannou A, Zarogoulidis P, Porpodis K, Spyratos D, Kioumis I, Pitsiou G, et al. Asthma-chronic obstructive pulmonary disease overlap syndrome (ACOS): Current literature review. J Thorac Dis. 2014;6 Suppl 1:S146-51. doi: 10.3978/j.issn.2072-1439.2014.03.04. [PubMed: 24672688]. [PubMed Central: PMC3966158].

28. Miravitlles M, Soler-Cataluna JJ, Calle M, Molina J, Almagro P, Quintano JA, et al. Spanish guideline for COPD (GesEPOC). Update 2014. Arch Bronconeumol. 2014;50 Suppl 1:1-16. doi: 10.1016/S03002896(14)70070-5. [PubMed: 24507959].

29. Soler-Cataluna JJ, Cosio B, Izquierdo JL, Lopez-Campos JL, Marin JM, Aguero R, et al. Consensus document on the overlap phenotype COPD-asthma in COPD. Arch Bronconeumol. 2012;48(9):331-7. doi: 10.1016/j.arbres.2011.12.009. [PubMed: 22341911].

30. Koblizek V, Chlumsky J, Zindr V, Neumannova K, Zatloukal J, Zak J, et al. Chronic obstructive pulmonary disease: Official diagnosis and treatment guidelines of the Czech Pneumological and Phthisiological Society; a novel phenotypic approach to COPD with patientoriented care. Biomed Pap Med Fac Univ Palacky Olomouc Czech Repub. 2013;157(2):189-201. doi: 10.5507/bp.2013.039. [PubMed: 23733084].

31. Kankaanranta H, Harju T, Kilpelainen M, Mazur W, Lehto JT, Katajisto $\mathrm{M}$, et al. Diagnosis and pharmacotherapy of stable chronic obstructive pulmonary disease: The finnish guidelines. Basic Clin Pharmacol Toxicol. 2015;116(4):291-307. doi: 10.1111/bcpt.12366. [PubMed: 25515181]. [PubMed Central: PMC4409821].

32. GINA-GOLD. Diagnosis of disease of chronic airflow limitation: Asthma, (ACOS) Caa-Cos. 2014, [cited August 5th, 2014]. Available from: http:// www.goldcopd.org/asthma-copd-overlap.html.

33. Hogg JC. Pathophysiology of airflow limitation in chronic obstructive pulmonary disease. Lancet. 2004;364(9435):709-21. doi: 10.1016/S0140-6736(04)16900-6. [PubMed: 15325838].

34. Corlateanu A, Covantev S, Mathioudakis AG, Botnaru V, Siafakas N. Ashtma-Chronic obstructive pulmonary disease overlap syndrome (ACOS): Current evidence and future research directions. COPD Res Pract. 2017;3(1). doi: 10.1186/s40749-017-0025-x.

35. McDonough JE, Yuan R, Suzuki M, Seyednejad N, Elliott WM, Sanchez PG, et al. Small-airway obstruction and emphysema in chronic obstructive pulmonary disease. N Engl J Med. 2011;365(17):1567-75. doi: 10.1056/NEJMoa1106955. [PubMed: 22029978]. [PubMed Central: PMC3238466].

36. Gelb AF, Yamamoto A, Verbeken EK, Nadel JA. Unraveling the pathophysiology of the asthma-COPD overlap syndrome: Unsuspected mild centrilobular emphysema is responsible for loss of lung elas- tic recoil in never smokers with asthma with persistent expiratory airflow limitation. Chest. 2015;148(2):313-20. doi:10.1378/chest.14-2483. [PubMed: 25950858].

37. Singh D, Kolsum U, Brightling CE, Locantore N, Agusti A, TalSinger R, et al. Eosinophilic inflammation in COPD: Prevalence and clinical characteristics. Eur Respir J. 2014;44(6):1697-700. doi: 10.1183/09031936.00162414. [PubMed: 25323230].

38. Christenson SA, Steiling K, van den Berge M, Hijazi K, Hiemstra PS, Postma DS, et al. Asthma-COPD overlap. Clinical relevance of genomic signatures of type 2 inflammation in chronic obstructive pulmonary disease. Am J Respir Crit Care Med. 2015;191(7):758-66. doi: 10.1164/rccm.201408-14580C. [PubMed: 25611785]. [PubMed Central: PMC4407484].

39. Hardin M, Cho M, McDonald ML, Beaty T, Ramsdell J, Bhatt S, et al. The clinical and genetic features of COPD-asthma overlap syndrome. Eur Respir J. 2014;44(2):341-50. doi: 10.1183/09031936.00216013. [PubMed: 24876173]. [PubMed Central: PMC4154588].

40. Miravitlles M, Huerta A, Fernandez-Villar JA, Alcazar B, Villa G, Forne $\mathrm{C}$, et al. Generic utilities in chronic obstructive pulmonary disease patients stratified according to different staging systems. Health Qual Life Outcomes. 2014;12:120. doi: 10.1186/s12955-014-0120-5. [PubMed: 25189786]. [PubMed Central: PMC4173058].

41. Barrecheguren M, Roman-Rodriguez M, Miravitlles M. Is a previous diagnosis of asthma a reliable criterion for asthma-COPD overlap syndrome in a patient with COPD? Int J Chron Obstruct Pulmon Dis. 2015;10:1745-52. doi: 10.2147/COPD.S87025. [PubMed: 26366067]. [PubMed Central: PMC4562730].

42. Golpe R, Sanjuan Lopez P, Cano Jimenez E, Castro Anon O, Perez de Llano LA. Distribution of clinical phenotypes in patients with chronic obstructive pulmonary disease caused by biomass and tobacco smoke. Arch Bronconeumol. 2014;50(8):318-24. doi: 10.1016/j.arbres.2013.12.013. [PubMed: 24576449].

43. Hardin M, Silverman EK, Barr RG, Hansel NN, Schroeder JD, Make BJ, et al. The clinical features of the overlap between COPD and asthma. RespirRes. 2011;12:127. doi: 10.1186/1465-9921-12-127. [PubMed: 21951550]. [PubMed Central: PMC3204243].

44. Soriano JB, Davis KJ, Coleman B, Visick G, Mannino D, Pride NB. The proportional Venn diagram of obstructive lung disease: Two approximations from the United States and the United Kingdom. Chest. 2003;124(2):474-81. doi: 10.1378/chest.124.2.474. [PubMed: 12907531].

45. Alshabanat A, Zafari Z, Albanyan O, Dairi M, FitzGerald JM. Asthma and COPD overlap syndrome (ACOS): A systematic review and meta analysis. PLoS One. 2015;10(9). e0136065. doi: 10.1371/journal.pone.0136065. [PubMed: 26336076]. [PubMed Central: PMC4559416].

46. Tho NV, Park HY, Nakano Y. Asthma-COPD overlap syndrome (ACOS): A diagnostic challenge. Respirology. 2016;21(3):410-8. doi: 10.1111/resp.12653. [PubMed: 26450153].

47. Marsh SE, Travers J, Weatherall M, Williams MV, Aldington S, Shirtcliffe PM, et al. Proportional classifications of COPD phenotypes. Thorax. 2008;63(9):761-7. doi: 10.1136/thx.2007.089193. [PubMed: 18728201]. [PubMed Central: PMC2862964].

48. Diaz-Guzman E, Khosravi M, Mannino DM. Asthma, chronic obstructive pulmonary disease, and mortality in the U.S. population. COPD. 2011;8(6):400-7. doi: 10.3109/15412555.2011.611200. [PubMed: 22149399].

49. Kitaguchi Y, Komatsu Y, Fujimoto K, Hanaoka M, Kubo K. Sputum eosinophilia can predict responsiveness to inhaled corticosteroid treatment in patients with overlap syndrome of COPD and asthma. Int J Chron Obstruct Pulmon Dis. 2012;7:283-9. doi: 10.2147/COPD.S30651. [PubMed: 22589579]. [PubMed Central: PMC3346210].

50. Fu JJ, Gibson PG, Simpson JL, McDonald VM. Longitudinal changes in clinical outcomes in older patients with asthma, COPD and asthma-COPD overlap syndrome. Respiration. 2014;87(1):63-74. doi: 10.1159/000352053. [PubMed: 24029561].

51. Postma DS, Reddel HK, ten Hacken NH, van den Berge M. Asthma 
and chronic obstructive pulmonary disease: Similarities and differences. Clin Chest Med.2014;35(1):143-56. doi:10.1016/j.ccm.2013.09.010. [PubMed: 24507842].

52. Lee H, Tho NV, Nakano Y, Lee BJ, Park HY. A diagnostic approach and natural course of a patient with asthma-COPD overlap syndrome. Respirol Case Rep. 2015;3(4):119-21. doi: 10.1002/rcr2.130. [PubMed: 26740875]. [PubMed Central: PMC4694594].

53. Papi A, Romagnoli M, Baraldo S, Braccioni F, Guzzinati I, Saetta M, et al. Partial reversibility of airflow limitation and increased exhaled NO and sputum eosinophilia in chronic obstructive pulmonary disease. Am J Respir Crit Care Med. 2000;162(5):1773-7. doi: 10.1164/ajrccm.162.5.9910112. [PubMed: 11069811].

54. Welte T, Miravitlles M, Hernandez P, Eriksson G, Peterson S, Polanowski T, et al. Efficacy and tolerability of budesonide/formoterol added to tiotropium in patients with chronic obstructive pulmonary disease. Am J Respir Crit Care Med. 2009;180(8):741-50. doi: 10.1164/rccm.200904-0492OC. [PubMed: 19644045].

55. Tashkin DP, Celli B, Decramer M, Liu D, Burkhart D, Cassino C, et al. Bronchodilator responsiveness in patients with COPD. Eur Respir J. 2008;31(4):742-50. doi: 10.1183/09031936.00129607. [PubMed: 18256071].

56. Tamada T, Sugiura H, Takahashi T, Matsunaga K, Kimura K, Katsumata U, et al. Biomarker-based detection of asthma-COPD overlap syndrome in COPD populations. Int J Chron Obstruct Pulmon Dis. 2015;10:2169-76. doi: 10.2147/COPD.S88274. [PubMed: 26491283]. [PubMed Central: PMC4608617].

57. Chou KT, Su KC, Huang SF, Hsiao YH, Tseng CM, Su VY, et al. Exhaled nitric oxide predicts eosinophilic airway inflammation in COPD. Lung. 2014;192(4):499-504. doi: 10.1007/s00408-014-9591-8. [PubMed: 24816967].

58. Iwamoto H, Gao J, Koskela J, Kinnula V, Kobayashi H, Laitinen $\mathrm{T}$, et al. Differences in plasma and sputum biomarkers between COPD and COPD-asthma overlap. Eur Respir J. 2014;43(2):421-9. doi: 10.1183/09031936.00024313. [PubMed: 23794464].

59. Huang AX, Lu LW, Liu WJ, Huang M. Plasma inflammatory cytokine IL-4, IL-8, IL-10, and TNF-alpha levels correlate with pulmonary function in patients with asthma-chronic obstructive pulmonary disease (COPD) overlap syndrome. Med Sci Monit. 2016;22:2800-8. doi: 10.12659/MSM.896458. [PubMed: 27501772]. [PubMed Central: PMC4982526].

60. Araujo D, Padrao E, Morais-Almeida M, Cardoso J, Pavao F, Leite $\mathrm{RB}$, et al. Asthma-chronic obstructive pulmonary disease overlap syndrome - Literature review and contributions towards a Portuguese consensus. Rev Port Pneumol (2006). 2017;23(2):90-9. doi: 10.1016/j.rppnen.2016.11.005. [PubMed: 28089081].

61. Cataldo D, Corhay JL, Derom E, Louis R, Marchand E, Michils A, et al. A Belgian survey on the diagnosis of asthma-COPD overlap syndrome. Int J Chron Obstruct Pulmon Dis. 2017;12:601-13. doi: 10.2147/COPD.S124459. [PubMed: 28243078]. [PubMed Central: PMC5315206].

62. Fu JJ, McDonald VM, Gibson PG, Simpson JL. Systemic inflammation in older adults with asthma-COPD overlap syndrome. Allergy Asthma Immunol Res. 2014;6(4):316-24. doi:10.4168/aair.2014.6.4.316. [PubMed: 24991455]. [PubMed Central: PMC4077958].

63. Harada T, Yamasaki A, Fukushima T, Hashimoto K, Takata M, Kodani
$\mathrm{M}$, et al. Causes of death in patients with asthma and asthma-chronic obstructive pulmonary disease overlap syndrome. Int J Chron Obstruct Pulmon Dis. 2015;10:595-602. doi: 10.2147/COPD.S77491. [PubMed: 25834418]. [PubMed Central: PMC4370684].

64. Ding B, Enstone A. Asthma and chronic obstructive pulmonary disease overlap syndrome (ACOS): Structured literature review and physician insights. Expert Rev Respir Med. 2016;10(3):363-71. doi: 10.1586/17476348.2016.1144476. [PubMed: 26789845]. [PubMed Central: PMC4819878]

65. Barrecheguren M, Esquinas C, Miravitlles M. The asthma-COPD overlap syndrome: A new entity? COPD Res Pract. 2015;1(1). doi 10.1186/s40749-015-0012-z.

66. Nagai AAH, Aoshiba K, Asano K, Hirata K, Ichinose M. Guidelines for the diagnosis and treatment of COPD. 3rd ed. Tokyo, Japan: The Japanese Respiratory Society. Medical Review Co. Ltd; 2010.

67. Brightling CE, Monteiro W, Ward R, Parker D, Morgan MD, Wardlaw AJ, et al. Sputum eosinophilia and short-term response to prednisolone in chronic obstructive pulmonary disease: A randomised controlled trial. Lancet. 2000;356(9240):1480-5. doi: 10.1016/S01406736(00)02872-5. [PubMed: 11081531]

68. Chanez P, Vignola AM, O'Shaugnessy T, Enander I, Li D, Jeffery PK, et al. Corticosteroid reversibility in COPD is related to features of asthma. Am J Respir Crit Care Med. 1997;155(5):1529-34. doi: 10.1164/ajrccm.155.5.9154853. [PubMed: 9154853].

69. McDonald VM, Higgins I, Wood LG, Gibson PG. Multidimensional assessment and tailored interventions for COPD: Respiratory utopia or common sense? Thorax. 2013;68(7):691-4. doi: 10.1136/thoraxjnl-2012202646. [PubMed: 23503624]. [PubMed Central: PMC3711365].

70. Siva R, Green RH, Brightling CE, Shelley M, Hargadon B, McKenna S, et al. Eosinophilic airway inflammation and exacerbations of COPD A randomised controlled trial. Eur Respir J. 2007;29(5):906-13. doi: 10.1183/09031936.00146306. [PubMed: 17301099].

71. Brightling CE, Bleecker ER, Panettieri RJ, Bafadhel M, She D, Ward $\mathrm{CK}$, et al. Benralizumab for chronic obstructive pulmonary disease and sputum eosinophilia: A randomised, double-blind, placebocontrolled, phase 2a study. Lancet Respir Med. 2014;2(11):891-901. doi 10.1016/S2213-2600(14)70187-0. [PubMed: 25208464]. [PubMed Central: PMC5082845].

72. Barnes PJ. Immunology of asthma and chronic obstructive pulmonary disease. Nat Rev Immunol. 2008;8(3):183-92. doi: 10.1038/nri2254. [PubMed: 18274560].

73. Wedzicha JA, Rabe KF, Martinez FJ, Bredenbroker D, Brose M, Goehring $\mathrm{UM}$, et al. Efficacy of roflumilast in the COPD frequent exacerbator phenotype. Chest. 2013;143(5):1302-11. doi: 10.1378/chest.12-1489. [PubMed: 23117188].

74. Lazarus SC, Chinchilli VM, Rollings NJ, Boushey HA, Cherniack R, Craig TJ, et al. Smoking affects response to inhaled corticosteroids or leukotriene receptor antagonists in asthma. Am J Respir Crit Care Med. 2007;175(8):783-90. doi: 10.1164/rccm.200511-1746OC. [PubMed: 17204725]. [PubMed Central: PMC1899291].

75. Li H, Yang T, Ning Q, Li F, Chen T, Yao Y, et al. Cigarette smoke extracttreated mast cells promote alveolar macrophage infiltration and polarization in experimental chronic obstructive pulmonary disease. Inhal Toxicol. 2015;27(14):822-31. doi: 10.3109/08958378.2015.1116644. [PubMed: 26671198]. 